\title{
ASSESSMENT THE IMPACT OF MORINGA OLEIFERA EXTRACTS AND ASCORBIC ACID SOLUTION AS ANTIOXIDANTS ON MICROSHEAR BOND STRENGTH OF RESIN COMPOSITE TO BLEACHED BOVINE ENAMEL (IN VITRO STUDY)
}

\author{
Mona Shaaban Mohamed* and Nawal Hassan Aidaros*
}

\begin{abstract}
Objective: The present study was conducted to assess the impact of Moringa Oleifera extracts and ascorbic acid solution on microshear bond strength of composite resin to bleached Enamel.

Methods: Twenty-five lower bovine incisors were randomly divided into five groups of 5 teeth each; Group I $(n=5)$ : Where no bleaching was done and no antioxidants were used, Group II $(n=5)$ : Where bleaching was done, but no antioxidants were used, Group III ( $n=5)$ (Positive control group): Bleaching followed by treatment with $10 \%$ Ascorbic acid solution for 10 minutes, Group IV ( $n=5)$ : Bleaching followed by treatment with $80 \%$ ethanol extract of Moringa Oleifera for 10 minutes, Group V ( $\mathrm{n}=5$ ): Bleaching followed by treatment with $80 \%$ methanol extract of Moringa Oleifera for 10 minutes. Resin composite was applied on labial enamel surfaces of all groups. The results obtained were explored for normality using Kolmogorov-Smirnov and Shapiro-Wilk tests and One-way ANOVA followed by Tukey post hic test.
\end{abstract}

Results: The results revealed statistically significant difference found between the five groups were $\mathrm{p}<0.001$ where the highest mean value (17.34 Mpa) was recorded for (Group I; No bleaching) followed by (9.22 Mpa) was recorded for (Group III; Ascorbic Acid treatment after bleaching). The least mean value (4.41 Mpa) wasrecorded for (group II; No antioxidant after bleaching). No statistically significant difference was found between (Group III =Ascorbic Acid treatment after Bleaching) and (Group IV= Ethanol extract of Moringa Oleifera treatment after Bleaching).

Conclusion: Using $10 \%$ Ascorbic acid solution could reverse the reduced bond strength after bleaching and Ethanol extract of Moringa Oleifera can be a future candidate to be used as antioxidant solution after bleaching if immediate bonding is to be carried out.

KEYWORDS: Antioxidants, Microshear bond test,Ascorbic acid solution, Moringa Oleifera Extracts, At office bleaching.

* Lecturer, Operative Dentistry Department, Faculty of Oral and Dental Medicine, Ahram Canadian University, 6 th of October, Egypt. 


\section{INTRODUCTION}

Nowadays, the main concern of most women and men is to have attractive beautiful white smile. Cosmotic dentistry become the new hot topic that focuses on the improvement of the overall smile appearance. Cosmotic dentistry includes bleaching of teeth, as well as using direct and indirect esthetic restorations. Dental bleaching is performed to regain the natural white appearance of teeth Dental bleaching agents (peroxides) causes release of reactive oxygen species. These oxygen molecules inhibit the polymerization of resin monomers and interfere with resin infiltration into etched enamel resulting in decrease of bond strength of adhesive restoration to tooth; with subsequent failure of obtaining long term clinical success. (1) Thus, it is advised by many studies to delay the adhesive application for certain time (from 24 hours to 2 weeks). (2,3) When immediate esthetic corrections after bleaching is mandatory to obtain the perfect smile in the same visit, antioxidant application become a must to trap the oxygen molecules. ${ }^{(4)}$ Sodium ascorbate (10\%) is non-toxic, widely used as antioxidant as it is effective in reversal the compromised shear bond strength immediately after bleaching. ${ }^{(5,6)}$ Recent attempts have been succeeded to use herbal extracts as natural antioxidants (as Moringa Oleifera, rosemary leaf extracts, Grape seed extracts, green tea) in medical researches for their strong antioxidant property. (7) Moringa Oleifera commonly known as (Miracle Tree) has many medicinal uses with high nutritional value throughout the world. ${ }^{(8)}$ Many studies reported that Moringa Oleifera leaves are rich source of vitamin C, Calcium, Phosphorous and Potassium. ${ }^{(9)}$

Moringa Oleifera act as natural antioxidants. The phenolic compounds present in the Moringa Oleifera leaves have a direct effect on its free radical scavenging activity. ${ }^{(10)}$ It was reported that different extracts of Moringa Oleifera showed varying degrees of antioxidant activity. Both methanol and ethanol were found to be the best solvents for the extraction of antioxidant compounds from Moringa leaves. The scavenging ability of the methanolic extract of Moringa Oleifera was comparable to ascorbic acid. ${ }^{(10,11)}$

Therefore, the aim of the present study was to evaluate and compare the microshear bond strength of resin composite to immediately bleached enamel treated with different extracts of Moringa Oleifera (Ethanol, methanol extracts) and ascorbic acid solutions.

\section{MATERIAL AND METHODS}

\section{Study Design}

Microshear bond strength of resin composite to unbleached enamel as well as to immediately bleached enamel treated with either Moringa Oleifera extracts (ethanol, methanol) or ascorbic acid were evaluated. Twenty-five lower bovine incisors were randomly divided into five groups of 5 teeth each; Group I $(n=5)$ : Where no bleaching was done and no antioxidants were used, Group II $(n=5)$ : Where bleaching was done, but no antioxidants were used, Group III ( $\mathrm{n}=5)$ (Positive control group): Bleaching followed by treatment with $10 \%$ Ascorbic acid solution for 10 minutes, Group IV ( $\mathrm{n}=5)$ : Bleaching followed by treatment with $80 \%$ ethanol extract of Moringa Oleifera for 10 minutes, Group V ( $\mathrm{n}=5)$ : Bleaching followed by treatment with $80 \%$ methanol extract of Moringa Oleifera for 10 minutes. Resin composite was applied on labial enamel surfaces of all groups.

\section{SAMPLE PREPARATION}

Twenty-five freshly extracted intact non-carious single-rooted incisor bovine teeth were obtained from a local slaughterhouse. Teeth were scraped with hand scaler and washed under running tap water to remove any residual tissues and debris. Teeth with caries, cracks, fractures, wear or developmental enamel defects were excluded from this study. 
The teeth were frozen to maintain freshness until required, then they were stored in distilled water to be ready to use. All the samples were decoronated by sectioning the roots $2 \mathrm{~mm}$ below the cementoenamel junction using carbide disc. ${ }^{(12)}$ All the specimens were embedded in autopolymerising acrylic resin block $(3.0 \mathrm{~cm} \times 3.0 \mathrm{~cm} \times 3.0 \mathrm{~cm})$ such that only the labial surface were exposed upward. ${ }^{(6)}$ The exposed flattened labial surfaces of enamel were polished using 600-grit silicon carbide paper to obtain flat and uniform enamel surfaces to facilitate bonding with composite. ${ }^{(13)}$

\section{Preparation of the Antioxidant Solutions}

\section{Moringa Oleifera Extract Preparation}

Moringa Oleifera leaves powder was purchased from the National Research Center (NRC). The Moringa Oleifera powder were extracted in solvents (80\% ethanol, $80 \%$ methanol extracts) by cold maceration technique. The powder was placed in a Stoppard container with the solvent and allowed to stand at room temperature for 1 day until the soluble matter had dissolved. ${ }^{(14)}$

\section{Ascorbic Acid Solution Preparation}

Ascorbic Acid powder (10 grams) was dissolved in $100 \mathrm{ml}$ distilled water to obtain $10 \%$ Ascorbic acid solution. ${ }^{(15)}$

\section{Bleaching Procedure}

All specimens were bleached except Group I (negative control group). The 20 labial enamel surfaces of bovine incisors were bleached using White smile chemically-activated bleaching gel (40\% hydrogen peroxide, WHITE smile, Germany) according to manufacturer instructions for $20 \mathrm{~min}$. The bleaching gel was completely rinsed off with water spray for 60 seconds, and the process was repeated one more time for a total of 2 cycles of bleaching. After bleaching, the remineralizing agent (Fluoride gel) was applied in 1.5 to $2 \mathrm{~mm}$ thickness and left for 10 minutes on the labial enamel surfaces. Then the enamel surfaces were rinsed under running water. $^{(16)}$

\section{Antioxidant Treatment After Bleaching}

Regarding group (II), after bleaching procedure, the labial enamel surface of each tooth was immediately subjected to bonding procedures without antioxidant treatment. Regarding to the other three groups, immediately after bleaching procedure, $10 \mathrm{ml}$ of $10 \%$ ascorbic acid solution was applied for 10 minutes on Group (III) specimens, 10 $\mathrm{ml}$ of $80 \%$ ethanol extract of Moringa Oleifera was applied for 10 minutes on the Group (IV) specimens and $10 \mathrm{ml}$ of $80 \%$ methanol extract of Moringa Oleifera was applied for 10 minutes on the Group (V) using micro-brushes. ${ }^{(17)}$ Afterward, the labial surfaces were rinsed with distilled water for 30 seconds then air dried for 15 seconds. ${ }^{(13)}$

\section{Bonding Procedure and Composite Resin Application}

Labial enamel surfaces of all specimens of all groups were acid-etched using $37 \%$ phosphoric acid (Total Etch etching gel, Ivoclar Vivadent, Schaan, Liechtenstein) for 15 seconds, rinsed with distilled water for 20 seconds and air dried for 15 seconds. Three consecutive coats of bonding agent Adper Single Bond (3M ESPE, Dental Products, St Paul, MN, USA) were applied to the labial enamel surfaces with agitation using microbrush, then gently air dried. ${ }^{(6)}$ Finally, the applied bonding agent was light cured for 20 seconds using Light Emitting Diode curing unit (LED) (Woodpecker Medical Instrument) at a light intensity of $1200 \mathrm{~mW} /$ $\mathrm{cm}^{2}$. This process was followed by resin composite build-up. A transparent polyethylene tygon tube $(2.35 \mathrm{~mm}$ external diameter and $0.7 \mathrm{~mm}$ internal diameter) obtained from a scalp vein infusion set, 23G (JMS Singapore PTE, LTD) was cut into small segments of approximately $1 \mathrm{~mm}$ in length using a sharp scissor. The segments were used as matrices to build up cylindrical resin composite units. ${ }^{(18)}$ 
Twenty-five polyethylene segments were used to aid in resin composite packing on the labial surface of each tooth. $1 \mathrm{~mm}$ of resin composite material (Voco, Amaris.) was injected inside each polyethylene segment in slight excess from the side to be bonded to the enamel. The resin composite was polymerized for 40 seconds using LED light curing unit (Woodpecker Medical Instrument). A digital caliber was used to confirm the height of resin composite cylinders $(1 \mathrm{~mm})$. Then, the specimens were stored in distilled water at $37^{\circ} \mathrm{C}$ for 24 hours. (18) After 24 hours, the specimens were removed from distilled water and jet dried. The polyethylene tygon segments were then cautiously removed using lancet no.11 leaving the resin composite cylinders bonded to enamel surface. ${ }^{(18)}$

All resin composite cylinders were checked using ( $\times 6)$ magnifying glass lens for any defect or air bubble, where if present the specimen was discarded.

\section{Microshear Bond Strenght Analysis}

Each specimen with its bonded resin composite cylinders was secured with the four tightening bolts to the lower part of the specially designed attachment jig (Kerr dental specialties, West Collins orange, USA). The attachment jig was in turn screwed into the lower fixed and the upper movable compartments of the testing machine (Model LRXplus; Lloyd Instruments Ltd., Fareham, UK) with a load cell of $5 \mathrm{kN}$. A wire loop ( $G \& H$, Wire co., USA) prepared from an orthodontic stainless steel ligature wire $(180 \mu)$ was wrapped around the bonded resin composite rod to be close as much as possible to its base. A shear load by tensile mode of force was applied via testing machine at a crosshead speed of $0.5 \mathrm{~mm} / \mathrm{min}$. ${ }^{(19)}$ Data were recorded using computer software (Nexygen-MT; Lloyd Instruments).

\section{Statistical Analysis}

The mean and standard deviation values were calculated for each group in each test. Data were explored for normality using Kolmogorov-Smirnov and Shapiro-Wilk tests, data showed parametric (normal) distribution. One-way ANOVA followed by Tukey post hic test was used to compare between more than two groups in non-related samples. The significance level was set at $\mathrm{P} \leq 0.05$. Statistical analysis was performed with IBM® ${ }^{\circledR}$ SPSS ${ }^{\circledR}$ Statistics Version 20 for Windows.

\section{RESULTS}

The mean and standard deviation values of Microshear bond Strength of different groups are presented in Table (1) and Figure (1). A statistically significant difference was found between (Group I=No Bleaching, No Antioxidant) and each of (Group II), (Group III), (Group IV) and (Group V) groups where $(\mathrm{p}<0.001)$. Also, a statistically significant difference was found between (Group $\mathrm{II}=$ No Antioxidant treatment after bleaching) and (Group III= Ascorbic Acid treatment after Bleaching) where $(\mathrm{p}<0.001)$, while no statistically significant difference was found between (Group II =No Antioxidant treatment after bleaching) and each of (Group IV= Ethanol extract treatment after Bleaching) and (Group V= Methanol extract treatment after Bleaching) where $(\mathrm{p}=0.098)$ and $(\mathrm{p}=0.900)$.

No statistically significant difference was found between (Group III =Ascorbic Acid treatment after Bleaching) and (Group IV= Ethanol extract treatment after Bleaching) where $(\mathrm{p}=0.052)$, while a statistically significant difference was found between (Group III = Ascorbic Acid treatment after Bleaching) and (Group V= Methanol extract treatment after Bleaching) groups where $(\mathrm{p}<0.001)$. Also, a statistically significant difference was found between (Group IV= Ethanol extract treatment after Bleaching) and (Group V= Methanol extract treatment after Bleaching) where $(\mathrm{p}=0.016)$. 
Table (1): The mean, standard deviation (SD) values of Microshear Bond Strength of different groups:

\begin{tabular}{|c|c|c|}
\hline \multirow{2}{*}{ Variables } & \multicolumn{2}{|c|}{ Microshear } \\
\cline { 2 - 3 } & Mean & SD \\
\hline Group I (No bleaching) & 17.34 & 1.44 \\
\hline $\begin{array}{c}\text { Group II (No antioxidant } \\
\text { after bleaching) }\end{array}$ & 4.41 & 0.58 \\
\hline $\begin{array}{c}\text { Group III (Ascorbic Acid } \\
\text { after bleaching) }\end{array}$ & 9.22 & 0.92 \\
\hline $\begin{array}{c}\text { Group IV(Ethanol extract } \\
\text { of Moringa after bleaching) }\end{array}$ & 6.68 & 2.35 \\
\hline $\begin{array}{c}\text { Group V(Methanol extract } \\
\text { of Moringa after bleaching) }\end{array}$ & 5.1 & 0.62 \\
\hline $\boldsymbol{p}$-value & \multicolumn{2}{|c|}{$<* 01 *$} \\
\hline
\end{tabular}

*; significant $(p<0.05) n s ;$ no significant $((p>0.05)$

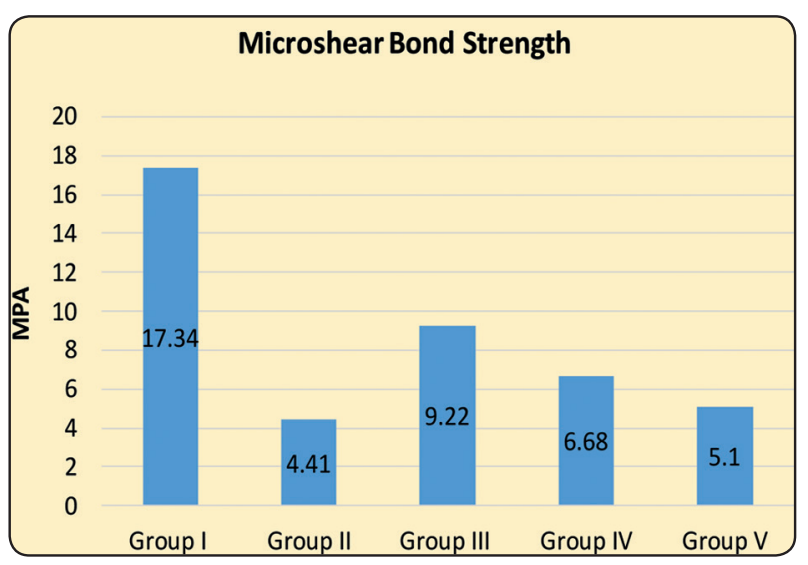

Figure (1): Bar chart representing Microshear Bond Strength of different groups.

\section{DISCUSSION}

In the daily dental clinic practice, tooth discoloration has always been a factor of utmost concern as more attention is being focused on Dental esthetics. With the developing awareness of esthetic options, there is a great demand for various treatment modalities for discolored teeth while conserving the tooth structure permitting a successful aesthetic outcome at minimal expense. ${ }^{(20)}$

Vital tooth bleaching procedure is the most commonly used conservative and effective treatment option to treat discolored teeth. (21) Peroxide containing bleaching agents remove tooth discolorations through oxidation. Hydrogen peroxide decomposes into oxygen and hydroxyl free radicals. ${ }^{(22)}$ The release of oxygen species may continue for several days. ${ }^{(1,23)}$ When bonding procedure is performed immediately after bleaching, the oxygen free radicals interfere with the resin infiltration into etched enamel resulting in poorly shaped resin tags in the enamel. In addition, the oxygen free radicals inhibit the resin polymerization resulting in reduced bond strength. $(24,25,26)$

Furthermore, reduced bond strength after bleaching could be due to the microstructure changes of bleached enamel surfaces such as reduced enamel microhardness and calcium loss. (22) An increase in peroxide concentration and gel acidity negatively affected microhardness as well as calcium and phosphorus content in enamel and dentin. ${ }^{(22,27)}$ Thus, it is advised by literatures to wait 24 hours to 3 weeks before carrying out a restorative procedure to avoid the reduced bond strength. ${ }^{(2,3,28,29)}$ Such waiting period may not be feasible in cases of immediate esthetic requirements. Considering this, various studies were undertaken to regain the reduced bond strength values and hence to carry out immediate esthetic corrections. ${ }^{(30,31,32)}$.

It was demonstrated that applying 10\% ascorbic acid to enamel after bleaching reverses the compromised bond strength. ${ }^{(5)}$ Ascorbic acid and its sodium salts are potent antioxidants with the capacity to quench reactive oxygen free radicals that may contribute to reduced bond strength. ${ }^{(5)}$ Hence, Ascorbic acid was used in the present study as it is the gold standard oxidizing agent that can be used as positive control group (Group III). The antioxidant characteristic is based on the ability to trap free radicals. Antioxidants may be derived from various sources like plants, animals and synthetic chemical preparations. However, synthetic antioxidants cause 
safety issues whereas animal-derived antioxidants face ethical issues. Many studies have encouraged the use of the plant extracts as alternative to synthetic antioxidants. An interest in antioxidant from natural sources increasing faster than synthetic sources. ${ }^{(33)}$ Natural antioxidants such as vitamin C, tocopherols, flavonoids and other phenolic compounds are known to be present in certain plants. ${ }^{(34)}$

It was previously demonstrated that application of pomegranate peel extract, grape seed extract, green tea, Aloe Vera on bleached enamel neutralized the effect of residual oxygen molecules and increased the shear bond strength of resin composite. (13) Among several plants, Moringa Oleifera is a plant that contain natural antioxidants such as flavonoids, phenolics, and carotenoids. (35,36,37) Therefore, the purpose of the current study was to evaluate the microshear bond strength of resin composite to immediately bleached enamel treated with Moringa Oleifera (Ethanol, methanol extracts) and Ascorbic acid solutions. Moringa Oleifera extracts and Ascorbic acid solutions were used as antioxidants in attempt to reverse the compromised bond strength of resin composite to extra-coronally bleached enamel. In the present study, since the antioxidant preparations were in solution form, individual resin molds were prepared for adequate contact of antioxidants with the labial surface of the specimens. ${ }^{(6)}$ According to Ram et al, 2014, $10 \mathrm{ml}$ of ascorbic acid, Moringa Oleifera extracts were applied on the enamel labial surfaces for $10 \mathrm{~min}^{(6)}$ In clinical scenario, molds can be substituted with customized trays that can be worn by the patient for an appropriate time. Bonded specimens were stored in deionized water for $24 \mathrm{~h}$ at $37^{\circ} \mathrm{C}$ before shear bond strength testing to artificially age the composite resins. ${ }^{(6,18)}$ Artificial aging simulates the chemical and physical oral environments, producing in a relatively short period, degradation similar to that which a composite resin would undergo in its clinical life. ${ }^{(38,39)}$
The positive and negative control groups used in this study clearly defined the difference in bond strength between unbleached and bleached enamel immediately restored with resin composite. Group I specimens (No bleaching group) as expected, showed the highest microshear bond strength when compared to the other groups, this may be due to absence of the residual oxygen layer as no bleaching was done. These findings were in accordance with other studies done by Subramonian $\mathrm{R}$ et al, and

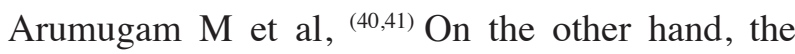
lowest microshear bond strength was observed in Group II (No antioxidant treatment after bleaching group) when compared to other groups; this may be due to the residual oxygen layer left behind following the bleaching process which could have interfered with the resin infiltration into etched enamel and inhibited the resin polymerization. $(24,25,38$,$) As a result, the oxygen-rich tooth structure$ does not provide a good surface for bonding. ${ }^{(26,38)}$ Moreover, it was previously reported that loss of calcium, sulfate, phosphorus, and potassium occurs due to the low $\mathrm{pH}$ of the bleaching agents. Such loss lead to structural alterations in the enamel, reducing the bond strength of the composite resin to the tooth. $(22,27)$

A similar result supporting this claim has been obtained in this study in group II (No antioxidant treatment after bleaching group). When the ascorbic acid solution was applied on bleached enamel (Group III specimens), the microshear bond strength of the adhesive to the bleached tooth surface was significantly higher than that of group II (No antioxidant treatment after bleaching group). These findings were in accordance with other studies ${ }^{(15,17)}$, this could be attributed to that ascorbic acid trap free oxygen radicals and permit adequate free-radical polymerization of adhesive resin thus improving the compromised bonding. ${ }^{(5,15,17,25,33)}$ The antioxidizing ability of ascorbic acid solution aided to reverse the oxidizing effects of the bleaching agent. ${ }^{(15,31,39)}$ Moreover, Arumugam et al, concluded 
that $10 \%$ sodium ascorbate showed significantly higher bond strength when compared to $6.5 \%$ proanthocyanidin and lycopene. ${ }^{(41)}$ This finding is in accordance with our current study as Group III specimens showed significantly higher microshear bond strength when compared to the group treated with Moringa Oleifera methanolic extracts (Group V). In contrary, Vidhya $S$ et al, stated that natural antioxidants such as grape seed extract showed 50 times more potent than sodium ascorbate; due to its oligomeric proanthocyanidin complexes content that have free-radical scavenging ability. ${ }^{(39)}$

In group IV \& V, ethanol and methanol extracts of Moringa Oleifera Leaves were applied on labial enamel surfaces as natural antioxidants immediately after bleaching for $10 \mathrm{~min} .{ }^{(6)}$ Many studies reported the antioxidant properties of Moringa Oleifera. $(9,10,11,35,36) \quad$ The leaf extract exhibits the greatest antioxidant activity when compared to other parts of the plant as flower and seeds. Moringa leaves contains the highest total phenolic content (105 $\mathrm{mg}$ gallic acid $/ 100 \mathrm{~g})$, the highest total flavonoid content (31 mg/100 g) and ascorbic acid content (107 $\mathrm{mg} / 100 \mathrm{~g}) .{ }^{(35,36)}$ It was found that Moringa leaves are rich in phenolic compounds such as flavonoids, gallic acid, quercetin and kaempferol. ${ }^{(10,11,42)}$ Thus, the leaves of Moringa Oleifera were used in the present study. Moringa Oleifera leaves had almost twice the TPC (total phenolic content) and threefold the TFC (total flavonoid content) of the vegetables (cabbage, spinach, broccoli, cauliflower and peas). Oxidizing ability of Moringa leaves were also much higher than those of the selected vegetables.

These findings suggested that Moringa Oleifera is a better source of antioxidants than are the common vegetables. ${ }^{(43)}$ A positive linear relationship was found to be present between polyphenolic content and scavenging activity of the extracts. ${ }^{(43)}$ Phenolics possessing at least one aromatic ring (C6) bearing one or more hydroxyl groups posses' ideal structural chemistry to scavenge free radicals. Flavonoids are probably the most important class of natural phenolics and have ability to donate electrons or hydrogen atoms readily, so they can directly scavenge reactive oxygen species. ${ }^{(44)}$

The antioxidant activity of Moringa extracts depends on the solvent used in the extraction. Both ethanolic and methanolic extracts exhibited higher antioxidant activity compared to aqueous extracts. ${ }^{(14,45)}$ The lowest TPC and flavonoid contents were obtained with aqueous extracts. (10) Therefore, ethanol and methanol extracts of Moringa Oleifera were used in the current study (group IV and group V respectively). No statistically significant difference was found between teeth treated with Ascorbic Acid after bleaching (Group III) and Ethanolic extract after bleaching (Group IV). Also, a statistically significant difference was found between (Group IV) and (Group V= Methanol extract treatment after Bleaching).

Thus the findings of the current study indicated that Ethanol extract of Moringa O. has higher antioxidant ability than that of methanol extract. Our results are compatible with Tomsone 2012 who stated that ethanol extract of Moringa O. was the best solvent to use. ${ }^{(46)}$ Our results were also in agreement with that of Nobossé P et al, 2018 who demonstrated that ethanol extract had the highest DPPH scavenging activities (53.3\%-71.1\%) for all ages followed by methanol extracts $(38.7 \%-55.0 \%)$ and aqueous extracts (15.6\%-20.6\%). In addition, it was reported that flavonoids were best extracted in ethanol.

The DPPH scavenging activity of Moringa Oleifera leaf ethanol extracts is strongly linked to the presence of chlorophyll and flavonoids. ${ }^{(46)}$ DPPH radical scavenging assay had been used widely to test the ability of compounds to act as free radical scavengers or hydrogen donors. This capability was used to evaluate antioxidant activity. (46) On the other hand, the present observations are in disagreement with other studies that reported that 
Methanol extract showed the highest antioxidant activity both in DPPH free radical scavenging and ABTS assay in vitro. ${ }^{(10)}$

The variation of phenolic and flavonoid contents with extraction solvent could be explained by the differences in polarity and diffusion strengths of the solvents or the selective solubility of phytochemicals in a given solvent. ${ }^{(45,48,49)}$ This work evaluated for the first time the impact of using Moringa Oleifera leaves extracts as antioxidants immediately after bleaching before carrying out bonding procedures. Thus, no previous published studies were reported to indicate the effective application time neither the effective concentration of the Moringa $\mathrm{O}$. extracts to effectively reverse the reduced bond strength of resin composite to bleached enamel. A possible explanation for the discrepancy between our results and some studies could be due to the application time of Moringa $\mathrm{O}$. extracts on bleached enamel (10 min.) was insufficient. Therefore, further investigations are needed to clarify the effect of different application durations of different extracts amounts and concentrations of Moringa $\mathrm{O}$. on microshear bond strength of resin composite to bleached enamel. Moreover, it was previously demonstrated that the antioxidant activity of the plant extracts can also be influenced by the agroclimatic conditions and the soil quality. ${ }^{(9,50)}$

\section{CONCLUSION}

Under the limitations of the current study it was concluded that: $10 \%$ Ascorbic acid solution could reverse the reduced bond strength after bleaching and Ethanol extract of Moringa Oleifera can be a future candidate to be used as antioxidant solution after bleaching if immediate bonding is to be carried out.

\section{RECOMMENDATIONS}

Further studies are recommended to assess the effect of different concentrations of different extracts of Moringa $\mathrm{O}$. as well as the effect of different application durations on bleached enamel.

\section{REFERENCES}

1. Attin T, Hannig C, Wiegand A and Attin R. Effect of bleaching on restorative materials and restorations - a systematic review. Dent Mater 2004; 20:852-861.

2. Je'Fferson D, Maria S, Renato H, Rodrigo S, Jader D and Maria L. The Influence of Time Interval between Bleaching and Enamel Bonding. J Esthet Restor Dent.2007; 19(2):111-119.

3. Cavalli V, Reis A, Giannini M, Ambrosano G. The effect of elapsed time following bleaching on enamel bond strength of resin composite. Oper Dent. 2001; 26:597-602.

4. Kum K, Lim K, Lee C. Effects of removing residual peroxide and other oxygen radicals on the shear bond strength and failure modes at resin-tooth interface after tooth bleaching. Am J Dent 2004; 17:267-270.

5. Türkün M and Kaya A. Effect of $10 \%$ sodium ascorbate on the shear bond strength of composite resin to bleached bovine enamel. J Oral Rehabil 2004; 31:1184-1191.

6. Ram S, Pavithra S, John T, Swapna P, Aseem S and Amit Shivrayan. An In Vitro Comparative Study of Shear Bond Strength of Composite Resin to Bleached Enamel using Synthetic and Herbal Antioxidants. J. Int. Oral Health 2014; 6 (6):77-81.

7. Mar M, Azizah A, Bablishah S, Farooq A, Sabu M and Pak-Dek M. Phenolic compounds and antioxidant activity of peanut's skin, hull, raw kernel and roasted kernel flour. Paki. J. Bot. 2011; 43(3), 635-642.

8. Farooq F, Rai M, Tiwari A, Khan A and Farooq S. Medicinal properties of Moringa Oleifera: An overview of promising healer. J. Med. Plants Res.2012; 6 (27): 43684374 .

9. Siddhuraju $\mathrm{P}$ and Becker K. Antioxidant properties of various solvent extracts of total phenolic constituents from three different agroclimatic origins of drumstick tree (Moringa oleifera Lam.) leaves. J. Agric. Food Chem. 2003; 51: 2144-2155

10. Wiwit D, Taslim E, Kuniyoshi S and Sri F. Antioxidant Activity of Moringa Oleifera Extracts. Indones. J. Chem. 2016; 16 (3): 297 - 301.

11. Andréa F, Adriana C, Patrícia M. and Luana C Antioxidant Activity of Moringa Oleifera Tissue Extracts. Phytother. Res. 2012; 26: 1366-1370.

12. Araújo D, Lucena $F$, Freitas $M$, Nunes L, Velo $M$, 
Magalhães A, et al, Effect of enamel pretreatment on the fluoride remineralization of artificial white spot lesions Braz Dent Sci 2018; 21(3): 328-334.

13. Sharafeddin F, Farshad F. The Effect of Aloe Vera, Pomegranate Peel, Grape Seed Extract, Green Tea, and Sodium Ascorbate as Antioxidants on the Shear Bond Strength of Composite Resin to Home-bleached Enamel Dent Shiraz Univ Med Sci. 2015; 16(4): 296-301.

14. Zhang Q, Lin L, Ye W. Techniques for extraction and isolation of natural products: a comprehensive review. Chin Med.2018; 13:20

15. Nari-Ratih D, Widyastuti A. Effect of antioxidants on the shear bond strength of composite resin to enamel following extra-coronal bleaching. J Clin Exp Dent. 2019;11(2):126132.

16. Nagi S, Hassan S, Abd El-Alim S, Elmissiry $M$. Remineralization potential of grape seed extract hydrogels on bleached enamel compared to fluoride gel: An in vitro study. J Clin Exp Dent. 2019;11(5):401-407.

17. Khosravanifard B, Rakhshan V, Araghi S, Parhiz H. Effect of Ascorbic Acid on Shear Bond Strength of Orthodontic Brackets Bonded with Resin-modified Glass-ionomer Cement to Bleached Teeth. J Dent Res Dent Clin Dent Prospect 2012; 6(2):59-64.

18. Sarı F, Şahin O, Özdemir A. Effect of dentin desensitizers and Nd:Yag laser pre-treatment on microshear bond strength of adhesive resin cement to dentin. Cum. Dent. J. 2019; 22(2).

19. Deepa V, Damaraju B, Priyadharsini B, Subbarao V, Raju K. Comparative Evaluation of Microshear Bond Strength of 5th, 6th and 7th Generation Bonding Agents to Coronal Dentin Versus Dentin at Floor of Pulp Chamber: An In vitro Study. J Int Oral Health 2014; 6(5):72-76.

20. Thickett E, Cobourne M. New developments in tooth whitening. The current status of external bleaching in orthodontics. J Orthodontics. 2009; 36:194-201.

21. Christensen G. Bleaching teeth: practioners trends. J Am Dent Assoc. 1997; 128:16S-18S.

22. Tezel H, Kemaloglu H. Susceptibility of enamel treated with bleaching agents to mineral loss after cariogenic challenge. In: Ming-yu Li, editor. Contemporary Approach to Dental Caries. 1 st ed. In Tech publishing company; Shangai, China: 2012:75-92.

23. Swift E. Critical appraisal. Reversal of compromised bonding after bleaching. J Esthet Restor Dent. 2012; 24:357-361.

24. Borges A, Rodrigues J, Borgues A, Marsilio A. The influence of bleaching agents on enamel bond strength of a composite resin according to the storage time. Rev Odontal UNESP 2007;36(1):77-83.

25. Kimyai S, Valizadeh H. The effect of hydrogel and solution of sodium ascorbate on bond strength in bleached enamel. Oper Dent. 2006; 31:496-499.

26. Lai S, Tay F, Cheung G, Mak Y, Carvalho R, Wei S, et al, Reversal of compromised bonding in bleached enamel. J Dent Res. 2002; 81:477-481.

27. Klaric E, Rakic M, Sever I, Milat O, Par M, Tarle Z. Enamel and Dentin Microhardness and Chemical Composition After Experimental Light-activated Bleaching. Oper Dent. 2015; 40(4):132-141.

28. Martin C, Mullins J, Kao E, Ngan P. Effect of Enamel Bleaching on Orthodontic Bond Strength-In Vitro. AADR 37th Annual Meeting and Exhibition 2008.

29. Gökçe B, Çömleko M, Özpinar B, Türkün M, Kaya A. Effect of antioxidant treatment on bond strength of a luting resin to bleached enamel. J Dent. 2008; 36:780-785.

30. Jefferson D, Maria S, Renato H, Rodrigo S, Jader D, Maria L. The Influence of Time Interval between Bleaching and Enamel Bonding J Esthet Restor Dent 2007; 19:111-119.

31. Torres C, Koga A, Borges A. The effects of antioxidant agents as neutralizers of bleaching agents on enamel bond strength. Braz J Oral Sci 2006;5(16):971-976.

32. Bulut H, Kaya A, Turkun M. Tensile bond strength of brackets after antioxidant treatment on bleached teeth. Eur J Orthod 2005;27(5):466-471.

33. Muraguchi K, Shigenobu S, Suzuki S, Tanaka T. Improvement of bonding to bleached bovine tooth surfaces by ascorbic acid treatment. Dent Mater J. 2007; 26:875881 .

34. Rice A, Nicholas M, Paul B, Peter B, John P. The relative antioxidant activities of plant-derived polyphenolic flavonoids. Free radical research.1995; 22(4): 375-383.

35. Alhakmani F, Kumar S, Khan S. Estimation of total phenolic content, in-vitro antioxidant and anti-inflammatory activity of flowers of Moringa Oleifera. Asian Pac J Trop Biomed. 2013; 3: 623-627.

36. Vongsak B, Sithisam P, Gritsanapan W. Simultaneous 
HPLC quantitative analysis of active compounds in leaves of Moringa Oleifera Lam. J Chromatogr Sci. 2014; 52: 641-645.

37. Razis A, Ibrahim M, Kntayya S. Health benefits of Moringa Oleifera. Asian Pac J Cancer Prev.2014; 15

38. Nour El-din K, Miller H, Griggs A, Wakefield C. Immediate bonding to bleached enamel. Oper Dent. 2006;31(1):10

39. Vidhya S, Srinivasulu S, Sujatha M, Mahalaxmi S. Effect of grape seed extract on the bond strength of bleached enamel. Oper Dent. 2011; 36(4):433-438.

40. Subramonian R, Mathai V, Christaine Angelo JB, Ravi J. Effect of three different antioxidants on the SBS of composite resin to bleached enamel. An in vitro study. J Conserv Dent. 2015; 18(2):144-148.

41. Arumugam M, Nesamani R, Kittappa K, Sanjeev K, Sekar M. Effect of various antioxidants on the SBS of composite resin to bleached enamel: An in vitro study. J Conserv Dent. 2015; 17 (1):22-26.

42. Santos F, Argolo C, Paiva M, Coelho L. Phytother. Res.2017; 26 (9): 1366- 1370.Fombang, \&Mbofung,

43. Pakade V, Cukrowska E, Chimuka L. Comparison of antioxidant activity of Moringa oleifera and selected vegetables in South Africa. S Afr J Sci. 2013;109(3/4), Art. 1154-1158.

44. Michalak A. Phenolic compounds and their antioxidant activity in plants growing under heavy metal stress. Pol J Environ Stud. 2006; 15(4); 523-530.

45. Sultana B, Anwar F, Ashraf M. Effect of extraction solvent/ technique on the antioxidant activity of selected medicinal plant extracts. Molecules 2009; 14: 2167-2180.

46. Tomsone L, Kruma Z, Galoburda R. Comparison of Different Solvents and Extraction Methods for Isolation of Phenolic Compounds from Horseradish Roots. Armoracia Rusticana.2012; 6(4).

47. Nobossé P, Fombang E, Mbofung C. Effects of age and extraction solvent on phytochemical content and antioxidant activity of fresh Moringa Oleifera L. leaves. Food Sci Nutr. 2018; 6:2188-2198.

48. Kumar V, Pandey N, Mohan N, Singh R. Antibacterial \& Antioxidant Activity of Different Extract Of Moringa Oleifera Leaves - An In-Vitro Study. Inter J.Pharm. Sci. Review and Research.2012; 12(1):89-94.

49. Medini F, Fellah H, Ksouri R, Abdelly C. Total phenolic, flavonoid and tannin contents and antioxidant and antimicrobial activities of organic extracts of shoots of the plant Limoniumdelicatulum. Journal of Taibah University for Science. 2014; 8:216-224.

50. Iqbal S and Bhanger M. Effect of season and production location on antioxidant activity of Moringa oleifera leaves grown in Pakistan. J Food Comp Anal. 2006; 19:544-551 .- 